\title{
Genetic basis of poor scholastic performance among children: A review
}

\author{
Kavita Singh, Dinesh Parmar and CBS Dangi \\ Department of Biotechnology, RKDF University, Bhopal (Madhya Pradesh) India
}

\begin{abstract}
This paper presents concise review on selective pioneering works and recent progress on the topic genetic basis of poor scholastic performance among children. Formal school education plays a great role in everyone's life. Poor scholastic performance may be the result of Intellectual disability or mental retardation which manifests under age 18. Interaction of certain genes and environmental conditions can result in intellectual disabilities. This provides ample definitions of concepts, classification, causes and consequences, prevalence, and involvement of chromosomes in mental disability cases. This reveals that the magnitude of genetic variations in mental deficiency and scholastic performance of children suggests strong genetic component.
\end{abstract}

KEY WORDS: SCHOLASTIC PERFORMANCE SCHOOL CHILDREN GENETIC REASONS

\section{INTRODUCTION}

Formal school education plays a great role in everyone's life. Unsettled poor scholastic performance poses instant and lifelong unfavorable effects on a child and adolescent's growth and cognitive development. Optimum cognitive development of a child influences his/ her learning behavior which is influenced by interaction of family, society, psychology, education, and economical atmosphere of the child. Poor scholastic perfor-

\section{ARTICLE INFORMATION:}

Received $6^{\text {th }}$ Oct, 2018

Accepted after revision $25^{\text {th }}$ Dec, 2018

BBRC Print ISSN: 0974-6455

Online ISSN: 2321-4007 CODEN: USA BBRCBA Thomson Reuters ISI ESC / Clarivate Analytics USA

Mono of Clarivate Analytics and Crossref Indexed Journal Mono of CR

NAAS Journal Score 2018: 4.31 SJIF 2017: 4.196

๑ A Society of Science and Nature Publication, Bhopal India 2018. All rights reserved.

Online Contents Available at: http//www.bbrc.in/

DOI: $10.21786 / \mathrm{bbrc} / 11.4 / 29$ mance is observed among some children (Carlson and Corcoran, 2001; Landry, 2014). Interactions of Gene and environment can result in different disease phenotypes and intellectual abilities (McKusick, 1983; Deary, 2012). All traits of an individual are products of heredity and environment interaction. Individuals with varied genotypes appear differently by exposure to the common environmental factors (Davies, 2016). Intelligence was one of the first human traits to be the target of genetic research even before psychology emerged as a scien- 
tific field. The correlation between DNA sequence and behavioral differences such as intelligence is considered causal because DNA variations can lead to behavioral differences but behavioral differences do not change DNA sequences (Deary et al., 2006; Sniekers et al., 2017).

\section{Intellectual disability and Poor Scholastic Performance}

The "poor scholastic performance" is a broad term and defined differently by scholars. Okoye (1982) defined poor scholastic performance as one in which a student is not successful in attaining standard performance in a specified evaluation exercises involving a test, an examination or a set of constant assessment. Poor scholastic performance may be the result of Intellectual disability or mental retardation which manifests under age 18 . American Association on Mental Retardation (AAMR) and American Psychiatric Association (APA) define mental retardation on the basis of certain formulations developed by them. This refers to extensive limitations in functioning characterized by radically sub-average intellectual level, existing concurrently with limitations in two or more of the following adaptive skill areas: communication ability, self-care, social skills, self-direction, community use, health and safety, leisure, home living and work (Luckasson et al. 1992).

The American Psychiatric Association (APA) is responsible for naming, defining, and describing mental disorders. Fifth edition of the Diagnostic and Statistical Manual of Mental Disorders (DSM-5), APA changed the term mental retardation and proposed the new term intellectual disability or intellectual developmental disorder.

\section{Definition of Concepts}

Defining mental retardation remains a challenge and a matter of controversy. Ever since people have been able to distinguish mental retardation from other forms of mental disability, a central theme of definitions has concerned the failure of mentally retarded persons to adapt adequately to their surroundings. Older definitions were couched in terms of adult behavior, and there was a tendency to avoid precise criteria for deciding in borderline instances.

Many writers have attempted to specify quantitative standards for deciding mental subnormal level. The most widely used objective criterion of this sort has been the score obtained on a standardized test of intelligence such as the Stanford-Binet Intelligence Scale or the Wechsler Intelligence Scale for Children (WISC). In 1916, Terman introduced a grouping of ability according to IQ's obtained on the Stanford-Binet (Terman and Merrill, 1937). This system became widely used and, in fact, became the standard classification system (Table 1). An IQ of 70 has gained considerable popularity as a cutoff score for the retarded group.
Doll (1953) provided more specific definition. In addition to the element of social adaptation, he emphasized the emergence of handicap in childhood, its constitutional nature and its incurability. He considered some criteria generally considered essential to an adequate definition and concept. These involve social incompetence, mental sub-normality, developmentally arrested, obtained at maturity, constitutional origin and essentially incurable. Tredgold (1956) defined mental deficiency as a state of incomplete mental development of such a kind and degree that the individual was incapable of adapting himself to the normal environment of his fellows in such a way as to maintain existence independently of supervision, control or external support.

The American Association on Mental Deficiency defines mental retardation as a significantly sub-average general intellectual function existing concurrently with deficits in adaptive behavior, and manifested during the developmental period. In this definition the retarded person is judged in terms of his success with the developmental tasks appropriate for his age: in the preschool period sensorimotor behaviors assume greatest importance, while during the school years academic ability is of first interest, and during adulthood economic independence and social recognition (Suess et al., 1983; APA, 2000). Furthermore, this definition makes it clear that a designation of mental status should be a description of present behavior and implicitly disowns the notion of potential intelligence.

There are a number of difficulties with these scoring criteria. Because an IQ is simply a score obtained on the basis of a restricted sample of behavior, there are significant limitations as to what can or should be expected of it, even if the tests are perfectly reliable and children are always able to put forth their best efforts. Furthermore, no cutoff score will ever be adequate to define mental retardation independent of the setting in which the individual finds himself. Different skills and abilities are required at different ages and in different environments. Retardation must therefore be gauged in large part against current environmental demands, (Reschly et al., 2002).

Apart from this, the cutoff scores for measures of intellectual function are better recognized than the cutoff scores for measures of adaptive behavior. There is open agreement in the major diagnostic systems that performance on the intellectual dimension must be approximately two or more standard deviations below the population mean, which translates into an IQ score of 70 or less on measures with a mean of 100 and a standard deviation of 15 (Reschly et al. 2002; Greene et al., 2004).

\section{Classification systems}

Mentally Retarded or intellectually disabled individuals comprise a very heterogeneous group both in their 


\begin{tabular}{|l|l|}
\hline \multicolumn{2}{|l|}{$\begin{array}{l}\text { Table 1. showing WHO List of Causal Factors of } \\
\text { Mental Retardation }\end{array}$} \\
\hline S. No. & Causal factors \\
\hline 1. & Infections and intoxications \\
\hline 2. & Trauma and physical agents \\
\hline 3. & Disorders of metabolism, growth or nutrition \\
\hline 4. & Gross brain damage (postnatal) \\
\hline 5. & $\begin{array}{l}\text { Diseases or conditions due to unknown prenatal } \\
\text { influences }\end{array}$ \\
\hline 6. & Chromosome abnormalities \\
\hline 7. & Prematurity \\
\hline 8. & Major psychiatric disorder \\
\hline 9. & Psycho-social (environmental) deprivation \\
\hline 10. & Other and unspecified \\
\hline $\begin{array}{l}\text { Source: } \text { WHO: Mental health: strengthening our response (www. } \\
\text { who.int/news-room/fact-sheets/detail/mental-health-strengthening- } \\
\text { our-response) }\end{array}$ \\
\hline
\end{tabular}

behavior and in the causes of their deficiency. Different classification systems have been proposed in the past to bring some order in this disarray. Most systems have approached the problem from one of three viewpoints: severity of the handicap, etiology of the symptoms, and the symptom collection.

\section{Additional criteria for classification}

Persons with mental retardation can also be grouped by age, an important criterion in education and longitudinal evaluation. Mainly for purposes of management, mental retardation can also be subdivided according to the biological syndrome. This classification offers advantages for special training and schooling in mentally retarded patients with associated deficits such as blindness, deafness, and spina bifida, (Halgin and Whiteborne, 2005).

\section{Causes and Consequences}

The causes of poor scholastic performance can be broadly classified into two groups that involve genetics and environment. The present study exclusively aims to focus on genetic causes of PSP however, discussion on medical and varied environmental factors remains imperative. There may be genetic basis of various medical problems associated with PSP, and many problems are purely environmental in their origin. Poor scholastic performance (PSP) shows multiple etiologies. Many reasons are responsible for poor scholastic performance of children involving specific learning disability, attention deficit hyperactivity disorder, low IQ level, emotional problems and psychiatric disorders. Other reasons involve a poor socio-cultural home environment and additional environmental causes, (Bruno and Njoku, 2012).

The causes of PSP can be further divided into extrinsic or environmental and intrinsic or individual factors. School difficulty (SD) and learning disability (LD) are two different manifestations of some school attending children. Former is related to pedagogical difficulties. Apart from diseases and related disabilities, pedagogical difficulties can also pose poor scholastic performance. It is extrinsic in nature with no possibilities of organic impairment (Siqueira and Gurge-Giannetti, 2011). Environmental reasons may infuse lack of interest in studies and distraction among some children may results in disappointment, frustration, low self-esteem and failure (Karande and Kulkarni, 2005).

Emotional causes are also important while considering poor scholastic performance being secondary to environmental factors involving lack of inspiration, low self-esteem and lack of sympathy and unresponsiveness (Valiente et al. 2012). It is argued that emotions influence school performance of children and that integrating cognition and emotion can demonstrate school performance and scholastic achievement in early formal education (Blair, 2002; Raver, 2002). Therefore, for a flourishing learning process, numerous cognitive skills associated with proper opportunities are essential.

Present work exclusively focuses on genetic causes of Poor scholastic performance hence; this largely involves Mental Deficiency (MD) which is again a developmental disability characterized by sub-mental level or lower than average intelligence of the age of a child. This is chiefly associated with biological causes that may show developmental delay or/and involvement of genes or chromosome. The investigation of the genetic basis of mental deficiency focuses mainly on identification of smaller and smaller chromosome variations associated with disease, (Raynham et al., 1996; Lucy Raymond and Tarpey, 2006).

The modest beginning of the investigation of the genetic basis of mental deficiency started long back in 1938 with a preliminary study of patients confined to hospital institutions (Penrose, 1938). In later years focus was on identification of smaller and smaller chromosome variations associated with disease (Raynham et al., 1996; Raymond and Tarpey, 2006 ).

Abnormal development of a child that leads to mental retardation may be due to trauma before birth caused by an infection or exposure to alcohol, drugs, or other toxins and trauma during birth caused by deprivation of oxygen or premature delivery of a new born child. Inherited disorders involve point mutation(s) and gross chromosomal abnormalities. Certain point mutations cause metabolic disorders that lead to mental retardation phenotype such as phenylketonuria (PKU). On the 
other hand, chromosomal abnormality such as Down syndrome demonstrates peculiar morphological and abnormal behavioral traits. The average IQ of matured persons with Down syndrome remains 50 that remain widely variable, (Malt et al. 2013).

\section{Prevalence}

Social integration of a moderately mental retardate will be more difficult in a competitive, industrialized community than in a rural environment with the long-term support of an old fashioned, extended family (Durkin et al. 1995). Almost all studies dealing with mental subnormality in children report a higher incidence in males than in females. Moreover, in addition to the data collected from population and institution surveys, recent studies of family pedigrees more specifically demonstrate that X-linked recessive disorders represent a substantial proportion of mentally retarded males (Raymond, 2006). The prevalence of mental retardation is influenced by a great number of environmental factors such as community, age, racial and ethnic background, geographic region, and sex (Hernandez and Blazer, 2006).

According to WHO estimates globally more than 450 million people suffer from mental disorders. Currently, mental and behavioral disorders account for $12 \%$ of the global burden of disease. This is likely to increase to $15 \%$ by 2020 . The major proportions of mental disorders come from low- and middle-income countries. The problem is further complicated by a lack of adequate trained manpower and a low priority of mental health in health policy (Reddy et al. 2013). The severely retarded are mostly identified before the age of one year, especially in the presence of physical abnormalities such as hydrocephaly, spasticity, and sensorial disturbances. Mildly mentally retarded individuals with IQ's ranging between 50 and 70 are recognized at school age (Boat and $\mathrm{Wu}, 2015)$.

In India, mental disorders have a prevalence of 1.05\%. Urban population has slightly higher rate being at $1.1 \%$ as compared to rural being at $1.008 \%$. Age was found to be highly correlated with prevalence among children of rural areas (Lakhan et al. 2015). Once the critical period of adolescence and school attendance is over, however, many of the mildly mentally handicapped are assimilated into society and join the ranks of the dull-normal, living for the most part in marginal socio economic circumstances.

\section{Genetic Disorders}

Genetic disorders are divided into two main groups. The first group includes chromosome disorders, such as Down syndrome, which may involve an entire chromosome including thousands of genes, while the second group involves only a single gene. Single gene disorders are divided into three main categories based on the mode of inheritance of the abnormal gene. The categories are autosomal recessive, autosomal dominant, and X-linked (Thompson and Thompson, 1986; Pradhan et al., 2011).

\section{Involvement of Chromosomes in Mental Disability}

There are genetic components to mental disability. Examination of persons with chromosomal variations and mental disabilities may be a way of overcoming difficulties faced with the proper diagnostic processes. Unfortunately, chromosomal analysis is rarely undertaken in subjects with psychiatric disorders. However, the rate of chromosomal abnormality has significantly increased in persons with learning disability, and may be as high as 20\% in those with mild learning disability (Gostason et al. 1991).It has been established in many other medical conditions with a genetic basis that chromosomal variations, either by direct gene disorder or by positional effects, can produce identical or similar phenotypes to those caused by point mutations and their existence has greatly facilitated the physical mapping and cloning of candidate genes (Collins, 1992, 1995).

Once a chromosomal anomaly is detected in a subject with mental disability, it may be considered noncoincidental and related to the disorder if one or more of the following criteria are met: (a) the chromosomal abnormality is rare and there are independent reports of the abnormality being associated with mental disability; (b) there is proximity of the abnormality with a region of suggestive linkage findings; or (c) there is co-segregation of the abnormality with mental disability within the patient's family, (Evans et al. 2001).

Some variations in chromosomes are very small and they only involve a single gene called single gene disorders. However, when variations in chromosomes are large enough and can be seen under light microscope, they are called chromosome anomalies or aberrations. There are many types of chromosome anomalies. Chromosome anomalies usually occur when there is an error in cell division following meiosis or mitosis. They can be organized into two basic groups viz. Numerical anomalies (aneuploidy or an abnormal number of chromosomes) and Structural anomalies. Numerical anomalies occur due to nondisjunction where abnormal numbers of chromosomes may find their way into gametes, and a disorder of chromosome numbers may result. Alteration in chromosome structure can take several forms described as under:

- Deletions: A portion of the chromosome is missing or deleted.

- Duplications: A portion of the chromosome is duplicated 
- Translocations: A portion of one chromosome is transferred to another chromosome. There are two main types of translocations:

Reciprocal translocation: Segments from two different chromosomes have been exchanged.

Robertsonian translocation: An entire chromosome has attached to another at the centromere

- Inversions: A portion of the chromosome has broken off, turned upside down, and reattached, therefore the genetic material is inverted.

There are two main types of Inversions:

Paracentric inversions: Both breaks occur in one arm of the chromosome and do not include the centromere

Pericentric inversions: Breaks occur in each arm of the chromosome and involved the centromere

- Insertions: A portion of one chromosome has been deleted from its normal place and inserted into another chromosome.

- Rings: A portion of a chromosome has broken off and formed a circle or ring. This can happen with or without loss of genetic material.

- Isochromosome: Formed by the mirror image copy of a chromosome segment including the centromere.

The chromosomes observed at metaphase stage possess two chromatids called sister chromatids. Chromatids of two different chromosomes are called non-sister chromatids. Conventionally, all the chromosomal aberrations are broadly divided into two groups.

Chromosome-type: In this type, breaks and re-joins always involve both sister-chromatids at any one locus.

Chromatid-type: In this type, breaks and re-joins always involve only one of the sister-chromatids at any one locus.

\section{Common Chromosomal Anomalies in Mental Deficiency}

\section{Down syndrome}

Down syndrome is unique in its prominent role in exploring biology of mental retardation for the first time in 1866 by John Longdon Down whose contribution was significant in understanding biology of normal and abnormal development (Down, 1866). The discovery of an extra 21 chromosome (trisomy 21) in the cells of individuals with Down syndrome exhibiting 47 chromosomes in place of 46 normal numbers by Professor Lejeune in 1959 established role of chromosome variations in development.

This was the discovery of chromosome aneuploidy in man that firmly established study of chromosome called cytogenetic as bona fide medical discipline (Smith and Warren, 1985; Patterson, 2009). Karyotype of normal human exhibits that chromosome 21 is one of the smallest autosomes, comprising nearly $1.9 \%$ of human DNA, Non-disjunction of this autosome during formation of the gametes at meiosis I or meiosis II in one of the parents result in Down syndrome. Down syndrome is the most common genetic form of mental retardation followed by X-linked mental retardation.

\section{Fragile $\mathrm{X}$ syndrome}

Fragile sites are heritable points on a chromosome which are susceptible to breakage and are consistently found on certain human chromosomes (Sutherland, 1982a, 1982b). These sites may represent structural chromosome mutations. Fragile X syndrome (FXS) causes learning disabilities and cognitive impairment. Usually, the penetrance of this genetic condition is higher in males as compared to females because males are hemizygous having single X-chromosome (McKusick, 1983). The maximum numbers of single genes that cause mental retardation are located on X chromosome. The first identified gene was FMR 1 that causes fragile $\mathrm{X}$ syndrome being the commonest single gene abnormality. The fragile site on the long arm of the $\mathrm{X}(\mathrm{Xq} 27.3$ ) is associated with a form of familial X-linked mental retardation (Lubs, 1969). It has been estimated that from one third to one half of all families with (nonspecific) X-linked mental retardation express the fragile site in some proportion of their cells (Brookwell et al, 1982).

The fragile site can be detected in chromosome preparations from lymphocytes grown in tissue culture media lacking folic acid and thymidine. Specific culture conditions can significantly alter the frequency with which the fragile site is expressed. Female carriers of this disorder may or may not express the fragile $\mathrm{Xj}$ some express it in only a small number of their cells. Thus, Xq fragile site demonstration in such carriers and in some affected males may be difficult due to a low level of expression. As with most $\mathrm{X}$-linked recessive disorders, carrier detection is an important: aspect of genetic counseling for families with this syndrome.

Males with fragile $\mathrm{X}$ syndrome show mild to moderate intellectual disability whereas considerable proportions of females with this disorder being nearly one-third remain intellectually disabled. Majority of males and nearly half the females with fragile $\mathrm{X}$ syndrome show characteristic morphological features involving long and narrow face, prominent jaw and forehead, flat feet, large ears and in males additionally enlarged testicles after puberty. A mutation of FMR-1 known as fragile-X mental retardation gene located on the $\mathrm{X}$ - chromosome causes this syndromic condition. The FMR1 gene codes a protein known as fragile $\mathrm{X}$ mental retardation protein (FMRP) required for normal brain development. Incidence was noted in all races and ethnic groups. Nearly 
10\% affected males have severe intellectual disability (Hagerman and Hagerman, 2002).

In fragile X syndrome, CGG pattern in a part of DNA in FMR 1 gene is repeated many times. In majority of persons, the number of repeats remains small at 5 to 44 repeats, which is common whereas; when the number of repeats is very high being greater than 200 repeats, the gene turns off and protein production is halted leading to development of FXS which is also known as trinucleotide repeat disorder. This is heritable condition transmitted from parents. Intermediate number of repeats at nearly 45 to 54 may have somewhat higher probability of having some symptoms but they do not have fragile $\mathrm{X}$ syndrome (Willemsen et al. 2011).

Sequence repeats in the range of 55-200 do not develop FXS but there may be development of other condition known as fragile $\mathrm{X}$-associated disorder. Couple with premutation can transmit this to their children with the same condition or full mutation leading to development of FXS (Gallagher and Hallahan, 2012).

The global prevalence of fragile X syndrome (FXS) in males is estimated nearly 1 in 4,000 while in females it is nearly 1 in 5,000. It has been demonstrated in both animal and human studies that changes in the environment radically impact behavior, (Restivo et al. 2005). A peaceful high quality home environment has been found associated with fewer autistic behaviors, higher IQ scores and better adaptability in children with Fragile $\mathrm{X}$ syndrome (Glaser et al. 2003).

The magnitude of genetic variations in mental deficiency and scholastic performance of children suggests strong genetic component. Genetic effects that influence general and verbal cognitive ability are largely responsible for scholastic performance. Remedial intervention remains a more immediately attainable goal while Subsequent research will entail more genetic analyses leading to identification of genes that influence academic achievement.

\section{REFERENCES}

APA (2000): Diagnostic and statistical manual of mental disorders, 4th ed. Washington, DC: American Psychiatric Association, USA.

Blair, C. (2002): School readiness. Integrating cognition and emotion in a neurobiological conceptualization of children's functioning at school entry. Am Psychol. 57(2):111-27

Boat, T.F. and Wu, J.T. editors (2015): Mental Disorders and Disabilities Among Low-Income Children. Washington (DC): National Academies Press (US);

Brookwell, R: Daniel, A; Turner, G; Fishburn, J. (1982): The fragile X(q27) form of X-linked mental retardation: FudR as an inducing agent for fraX(q27) expression in lymphocytes, fibroblasts and amniocytes. Am J Med Genet, 13: 139-148.
Bruno, U.D.O. and Njoku, J. (2012): Classroom Management of Mental Retardation. International Journal of Learning \& Development, 2(5): 105-111.

Carlson, M. J. and Corcoran, M. E. (2001): Family structure and children's behavioral and cognitive outcomes. Journal of Marriage and Family, 63:779-792.

Davies, G; Marioni, R E; Liewald, D C; Hill, W D; Hagenaars, S P; Harris, S E. et al. (2016): Genome-wide association study of cognitive functions and educational attainment in UK Biobank ( $N=112$ 151). Molecular Psychiatry,21: 758-767.

Deary, I. J, Spinath F.M; Bates T.C. (2006): Genetics of intelligence. European Journal of Human Genetics, 14, 690700.

Deary, I.J. Intelligence. Annu. Rev. Psychol. 63, 453-482 (2012) Doll, Edgar A The Measurement of Social Competence: A Manual for the Vineland Social Maturity Scale1953MinneapolisEducational Test Bureau (720 Washington Avenue, S. E.)641

Down, J. L. H. (1866): Observations on an Ethnic Classification of Idiots. London Hospital Reports, 3:259-262,

Durkin, M.S; Wang, W; Shrout, P.E; Zaman, S.S; Hasan, Z.M; Desai P, et al. (1995): Evaluating a ten question screen for childhood disability

Evans K.L; Muir, W.J; Blackwood, D.H; Porteous, D.J. ( 2001): Nuts and bolts of psychiatric genetics: building on the Human Genome Project. Trends 92 Genet; 17: 35-40

Gallagher, A, and Hallahan B. (2012): Fragile X-associated disorders: a clinical overview. J Neurol. , 259(3):401-413.

GlaserB, Hessl D, Dyer-Friedman J, et al. Biological and environmental contributions to adaptive behavior in FXS. Am J Med Genet A. 2003;117A (1):2-29.

Gostason, R; Wahlstrom, ;Johannisson, T; Holmqvist, D. (1991): Chromosomal aberrations in the mildly mentally retarded. $\mathrm{J}$ Men Defic Res; 35: 246- 246.

Greene, B. A; Miller, R. B; Crowson, H. M; Duke, B. L; Akey, K. L. (2004): Predicting high school students' cognitive engagement and achievement: Contributions of classroom perceptions and motivation. Contemporary Educational Psychology, 29, $462-482$.

Hagerman, R.J. and Hagerman, P.J., editors. (2002): FXS: diagnosis, treatment, and research. Baltimore (MD): Johns Hopkins University Press.

Halgin, R. and Whiteborne, K. (2005). Abnormal Psychology. New York: McGraw Hill.

Hernandez, L.M; Blazer, D.G; editors.(2006):Genes, Behavior, and the Social Environment: Moving Beyond the Nature/Nurture Debate. Washington (DC): National Academies Press (US).

Karande S, Kulkarni M. (2005): Poor school performance. Indian J Pediatr. ,72:961-7.

Lakhan, R; Ekúndayò, O. T; Shahbazi, M. (2015). An estimation of the prevalence of intellectual disabilities and its association with age in rural and urban populations in India. Journal of Neurosciences in Rural Practice, 6(4), 523-528 
Landry, S.H. (2014): The role of parents in early childhood learning. Encyclopedia on Early Childhood Development, USA.

Lubs, H. A. (1969): A marker X chromosome. Am. J. Hum. Genet, 21: 231-244.

Luckasson, R., Coulter, D. L., Polloway, E. A., Reiss, S., Schalock, R. L., Snell, 98 M. E., Spitalnick, D. M., \&t Stark, J. A. (1992): Mental retardation: Definition, classification, and systems of supports (9th Edition). Washington, DC: American Association on Mental Retardation

Lucy Raymond, F. and Tarpey, P.(2006): The genetics of mental retardation. Human Molecular Genetics, 15(1): 110-116.

Malt, EA; Dahl, RC; Haugsand, TM; Ulvestad, IH; Emilsen, NM; Hansen, B; Cardenas, YE; Skøld, RO; Thorsen, AT; Davidsen, EM (2013): Health and disease in adults with Down syndrome. TidsskrNorLegeforennr. 133 (3): 290-294.

McKusick, V.A. (1983): Human Genetics. 3rd Edition, PrenticeHall foundations of modern genetics series.

Okoye, N. N. (1982). Why students fail examinations: Psychology for everyday living; A Nigeria Journal of Applied Psychology 11(2): $1-5$.

Patterson D (2009): Molecular genetic analysis of Down syndrome. Hum Genet. 126(1):195-214.

Penrose, L. S. (Lionel Sharples) (1938): A clinical and genetic study of 1280 cases of mental defect. H. M. Stationery off, London.

Pradhan, S; Sengupta, M; Dutta, A; Bhattacharyya, K; Bag, S.K; Dutta, C; Ray, K. (2011): Indian genetic disease database, Nucleic Acids Research, 39(suppl_1):933-938.

Raver, C.C. (2002); Emotions matter: Making the case for the role of young children's emotional development for early school readiness. Social Policy Report, Society for Research in Child Development. 16:3-18.

Raymond, F. L. (2006). X linked mental retardation: a clinical guide. Journal of Medical Genetics, 43(3), 193-200.

Raynham, H; Gibbons, R; Flint, J; Higgs, D. (1996): The genetic basis for mental retardation, 89(3):169-175.

Reddy, V.B; Gupta, A; Lohiya, A, Kharya, P..(2013): Mental health issues and challenges in India. IJSER, 3:1-3.
Reschly, D.J; Myers, T.G; Hartel, C.R. Editors (2002): Mental Retardation: Determining Eligibility for Social Security Benefits, National Research Council (US) Committee on Disability Determination for Mental

Restivo L, Ferrari F, Passino E ( 2005): Enriched environment promotes behavioral and morphological recovery in a mouse model for the FXS. Proc Natl AcadSci U S A.;102 (32):115-57 .

SiqueiraI, C. M. and Gurge-Giannetti, J. (2011). Poor school performance: an updated review. Revista da Associação Médica Brasileira, 5(1): 78-8

Sniekers, S; Stringer, S; Watanabe, K; Jansen, P.R; Coleman, J.R.I; Krapohl, E. et al. (2017): Genome-wide association metaanalysis of 78,308 individuals identifies new loci and genes influencing human intelligence. Nature Genetics, 49:11071112.

Suess, J.F; cotton, P.D; Sison, G.F. Jr (1983): The American Association on Mental Deficiency--adaptive behavior scale: allowing credit for alternative means of communication. Am Ann Deaf, 128(3):390-393.

Sutherland. G. R. (1982b): Heritable fragile sites on human chromosomes, IX.Population cytogenetic and segregation analysis of the BrdU-requiring fragile site at 10q25. Am. J. Hum. Genet, 34: 753-756.

Terman, L. M. and Merrill, M. A. (1937): Measuring Intelligence: A Guide to the Administration of the New Revised Stanford-Binet Tests of Intelligence. Boston Houghton Mifflin Co461.

Thompson, J.S. and Thompson, M.W. (1986): Genetics in Medicine. W.B Saunders Co., Philadelphia, Pennsylvania.

Tredgold, A. F., and Soddy, K. 1956. A textbook of mental deficiency. 9th ed. Baltimore: Williams \& Wilkins

Valiente, C., Swanson, J., \&t Eisenberg, N. (2012). Linking Students' Emotions and Academic Achievement: When and Why Emotions Matter. Child Development Perspectives, 6(2), 129135

Willemsen, R., Levenga, J., and Oostra, B. A. (2011): CGG repeat in the FMR1gene: size matters. Clinical Genetics, 80(3), 214-225 